\title{
Application of a Choice Experiment to Estimate Farmers Preferences for Different Land Use Options in Northern Tajikistan
}

\author{
Manuchehr Goibov ${ }^{1}$, Peter Michael Schmitz ${ }^{1}$, Siegfried Bauer ${ }^{2} \&$ Mirza Nomman Ahmed ${ }^{1}$ \\ ${ }^{1}$ Department of Agricultural and Development Policy, Justus-Liebig University of Giessen, Giessen, Germany \\ ${ }^{2}$ Department of Project and Regional Planning, Justus-Liebig University of Giessen, Giessen, Germany \\ Correspondence: Manuchehr Goibov, Department of Agricultural and Development Policy, Justus-Liebig \\ University of Giessen, Senckenbergstr. 3, 35390, Giessen, Germany. Email: \\ manucher.goibov@agrar.uni-giessen.de
}

Received: February 21, 2012 Accepted: March 23, 2012 Online Published: May 1, 2012

doi:10.5539/jsd.v5n5p2

URL: http://dx.doi.org/10.5539/jsd.v5n5p2

\begin{abstract}
Based on farmers' preferences this study estimates the non-market values of agri-environmental attributes and their changes within the study area. The analysis is carried out using a choice experiment technique of stated-preference to conduct investigations regarding different land use options within the agricultural sector of the Konibodom region of Tajikistan. The dataset was constructed using a detailed household level survey amongst 117 representative farmers throughout the district, including all agriculturally important settlements. Detailed focus group discussions and a combination of personal interview and 'pick and drop' approaches were selected as the appropriate surveying techniques. In order to compliment the survey data, secondary data was collected from official statistics, key informants and experts from the field. Several types of models were specified and estimated such as Conditional Logit and Random Parameter Logit (RPL) Models. Significant improvements were achieved through the inclusion of interaction terms into the RPL model. The results of both the RPL models reveal that preference heterogeneity exists amongst farmers in the study area, implicating that a decision for land allocation under different crops is jointly associated with other socio-economic and environmental factors, influencing one another.
\end{abstract}

Keywords: choice experiment method, conditional logit model, random parameters logit model, agricultural land use, preference heterogeneity, Tajikistan

\section{Introduction}

Tajikistan is situated between $36^{\circ} 40^{\prime}$ and $41^{\circ} 05^{\prime}$ north latitude and $67^{\circ} 31^{\prime}$ and $75^{\circ} 14^{\prime}$ east longitude. Agriculture in Tajikistan is a stronghold of the country's economy and plays a significant role in food security as well as poverty eradication. Ongoing land and agrarian reforms have served as a driving force to move towards an increase in agricultural production; however it is still far apart from the pre independence period growth rates. It is a mountainous country, with around $93 \%$ of the territory covered by mountains. According to SLC land fund updates as of 01.01 .2008 , the whole territory consists of $14.25 \mathrm{mln}$. hectares, out of which 851 thousand hectares are intensively used for agricultural purposes. The fact that nearly $40 \%$ of the irrigated land is maintained by pump irrigation reveals the high energy needs of the sector. As the reforms in the sector are ongoing, the numbers of land users are also increasing gradually. Around $10 \%$ of the total territory that inhabits more than $60 \%$ of total population is characterized by high levels of anthropogenic destruction of natural ecosystems. Although it is a sector where more than $60 \%$ of the country's workforce is concentrated, the share of the sector's contribution to the country's GDP has been dwindling over the last years from 36\% in 1996 to 19.9 in 2008. In the post independence time period due to land degradation (i.e. soil erosion, water logging, etc.) the total area of arable land was reduced by up to $3.2 \%$ (SLC, 2008; SSC, 2009), which is a significant loss for the land resources lacking country. Low productivity of agricultural production, malfunctioning of irrigation systems and the degradation of pastures amongst other factors were found to effect the biodiversity of agro ecosystems (Fourth National Report on Biodiversity Conservation [FNRBC], 2009). Only 3\% of the total territory is covered with forests. Inefficient non-research based approaches for the formulation of appropriate policies for natural resources use in agriculture and poor land management knowledge resulting from the lack of familiarity with environmental issues, have been found to be predominantly responsible for the current critical environmental situation in the country. The environmental profile of the Soghd region (northern Tajikistan), which has been 
ranked as the most heavily degraded semi-desert mountain - and steppe conifer forest area in the country, in line with the NAP (National Action Plan) reveals the problems linked to environmental degradation: threat to endemic plant species due to overgrazing (e.g. Isfara district); improper functioning of irrigation systems (National Environmental Action Plan [NEAP], 2006).

According to a report by the UNECE (2004), the country's landscapes are home to 9771 florae and 13351 fauna species. Out of 84 different mammal species, 2 are lost and 12 are under the threat of disappearing. The law on environmental protection serves as a main legal basis for defining the framework for regulating biodiversity protection and landscapes preservation.

In Tajikistan, there are seven categories of land, which are defined within the framework of the total land fund in the country. These include areas under agricultural production, national reserves and historical areas, forestry, industrial and transport areas, state reserve, residential areas and lands of the state fund. Forest land and pastures in Tajikistan are claimed as state property, whereas agricultural land, following the land reform process in the early nineties, had been allocated to the population on a long-term use basis. Referring to the State Statistical Committee (2008), around $75 \%$ of the former collective and state farms have been reorganized in to more than thirty thousand privately owned dehkan (Note 1) farms. The reforms in the sector are still ongoing.

The legislative and regulatory framework concerning the land use and land resources protection mainly stems from the Land-, Forest- and Water Codes of the Republic of Tajikistan and other related Laws. Sheraliev (2009) analysing the period of 1991-2007 however stated, that although within the independence period a number of legislations were enacted taking environmental factors into account amid decision making processes, to date there is no clear implementation mechanism to incentivize land users to reduce environmental pollution. The post-independence period in Tajikistan was particularly characterized by a rapid pace of degradation, especially of agricultural and grasslands impacting the development of the agricultural sector at large.

Given the current economic conditions, with export orientation and commercial focus of agriculture (GoT, 2007; 2009), farmers in Tajikistan are primarily interested in their farms opulence, whereas issues like natural resources upkeep are sidestepped in most of the cases. This is mainly due to the limited knowledge that farmers possess on environmental matters. Although at a first glance the land use patterns amongst Tajik farmers appear to be different, whilst coming down to district and locality levels, identical farming systems with the variation of a few types of crops are found. Another issue worth considering is the unemployment in the agricultural sector, where most of the labourers due to the meagre salaries are apt to migrate, mainly to Russia and other former Soviet Union countries.

In most of the cases socio-economic factors are considered to be the main driving force for agricultural sector development. It is, however, another confirmation that environmental factors are omitted, which in sequence brings threat to ecological security as well as food security of the country. However, it is recognized that agriculture has more value than the value of goods produced within the sector alone. Referring to Schmitz et al. (2003), today's agriculture represents a special economic activity which is characterized by its rigorous assimilation with its natural environment. Several studies mainly focusing on land have been carried out. Ergasheva (2009) for instance, brought to light the issue of agricultural sector ecologization via an array of measures introduced by the state which in turn could reverse the tide of negative consequences on agro ecosystems. The main limitation in environmental management problems research in agriculture is their non-complexity and incompleteness, where the interrelationship between "environment-agricultural productions" is simply misplaced (Aidarov \& Korolkov, 2003). In addition, the linkage between land use decision making systems, rural development initiatives and the prevailing policy environment is poorly developed. Despite numerous analyses conducted focusing on land, one important research gap, where specific investigations regarding different land use options within the agricultural sector are tested, is still hardly filled. In this regard, an analysis that helps figure out which land use options can be best applied where (based on their suitability and benefits) with minimal impact on the environment is vitally important.

Therefore the main objectives of this paper are 1) to explore the applicability of Choice experiment in the country; and 2) based on farmer's preference to estimate the non-market values of agri-environmental attributes and their changes within the study area.

This paper is organized as follows: Section 2 gives an overview on the conceptual methodology which is followed by Study area description in section 3. Section 4 provides the methodological approach for the choice experiment. Results are discussed in Section 5, and finally section 6 concludes. 


\section{Materials and Methods}

\subsection{The Choice Experiment}

Theoretical background for the CM dates back to the Lancasterian model of consumer choice (Lancaster, 1966), and random utility theory (RUT) which was developed by Thurstone (1927). The econometric basis for the current choice modelling theory stems from McFadden $(1974 ; 1978)$, who later extended RUT to multiple comparisons and choices (McFadden \& Train, 2000). Following Lancaster, consumers gain their utility not from goods, but rather from the attributes these goods render. In our case, we consider the farmers preference for a land use option, assuming that the utility farmers derive from one or another land use option within a particular choice set lets say $\mathrm{C}$, consists of all attributes related to these options. Thus, the functional form which assumes farmers utility function looks as follows:

$$
U i j=V(Z i j, S i)+\varepsilon_{i}
$$

Where for any of the i-farmers, a certain level of utility he or she derives is linked to any other land use options $\mathrm{j}$. $\mathrm{Z}$ - denotes the attributes of the land use options $\mathrm{j}$, the farmer-i derives utility from. Further as RUT proposes, the farmer's utility level associated with the choice of land use option $\mathrm{j}$ includes observable, like a V-vector of attributes describing the goods which affects the farmers preferences complemented by S-socio-economic characteristics of the farmers, and stochastic- $e_{i}$ components respectively. All other unobservable factors having impact on the decision process of farmers are captured by stochastic component e. Conventionally, it is assumed that the farmers will choose an option which gives the greatest utility. Thus, following Ben-Akiva and Lerman (1985), the probability that a farmer $-\mathrm{i}$ chooses alternative $-\mathrm{j}$, amongst other alternatives within the given choice set $\mathrm{C}$ is formulated as follows:

$$
P_{i}(j)=\operatorname{Pr}\left(U i j \geq U i m, \quad \forall_{m} \in C i, j \neq m\right)
$$

Since the utility of each alternative here are divided into two, namely observable and error term components, we rewrite the equation (2) to include aforementioned components:

$$
P_{i}(j)=\operatorname{Pr}\left(V\left(Z_{i j}, S_{i}\right)+\varepsilon_{i j} \geq V\left(Z_{i m}, S_{i}\right)+\varepsilon_{i m}, \quad \forall_{m} \in C i, j \neq m\right)
$$

Further, if the dependant variables take three or more values, a multinomial logit model is employed. Encompassed by other probabilistic models, multinomial logit model implies that the condition of independently and identically distributed stochastic component or in other terms error terms must come across in line with a Gumbel distribution, namely IIA property (Luce, 1959). This shows that the relative probabilities of selecting between two options will remain unchanged by the introduction or removal of other options. Choice experiments are therefore, consistent with utility maximization and demand theory, when a status quo option, in other words comparator is included in the choice sets, which in turn ensures precise estimation of monetary welfare measures (Bateman et al., 2002). Assuming equation (1) $\forall_{m} \in C i$, for the computational purposes the multinomial logit or conditional logit, results in a conditional indirect utility function taking a linear functional form and can be written as (McFadden, 1974):

$$
V i j=\mu(\beta+\beta 1 Z 1+\beta 2 Z 2+\ldots+\beta n Z n+\beta a S 1+\beta b S 2+\ldots+\beta m S j)
$$

Where $\beta$ denotes the ASC (Alternative specific constant), representing the utility of zero payment option and in this study, defined as a 'status quo'. The vector of attributes of the land use options are represented by coefficients $\beta_{1}$ to $\beta_{\mathrm{n}}$, and $\beta_{\mathrm{a}}$ to $\beta_{\mathrm{m}}$. $\mathrm{S}_{1}$ to $\mathrm{S}_{\mathrm{j}}$ stand for socio-economic characteristics of the farmers. In view of the fact that, the socio-economic characteristics of the farmers are seen to be constant during the whole process of choices made for a particular farmer, they are regarded as an interaction term in this utility function. $\mu$ is a scale parameter which is assumed to be greater than zero, and is inversely proportional to the standard deviation of the error terms (Ben-Akiva \& Lerman, 1985; Bateman et al., 2002). Logit models are basically estimated via employment of maximum likelihood procedure.

Thus, right after parameter estimations are accomplished, a measure of economic value can be calculated for each land use options attributes using the following equation:

$$
\mathrm{CS}=\frac{\ln \sum_{k} \exp (V k i)-\ln \sum_{k} \exp (V k o)}{\alpha}
$$

Where CS is the compensating surplus welfare estimate, $\alpha$ is the marginal utility of income, which represents the coefficient of monetary attribute in the choice experiment, $V k i$ and $V k o$ are indirect utility functions before and after the change under consideration. Following Hanemann (1984), the reduced form of equation (5), looks as follows: 


$$
\mathrm{W}=-1\left(\frac{\beta a t t r i b u t e}{\beta \text { monetaryattribute }}\right)
$$

The ratios above represent a marginal implicit prices or in other words marginal rate of substitution between land use attributes and money.

\subsection{Application}

A number of studies conducted in the central Asian region, and especially in Tajikistan, are mainly related to environmental appraisal methods (WB, 2008), revealing that the concept of environmental goods valuation is almost new for the post soviet countries like Tajikistan. The demand for non-market valuation came into increasing consideration over the past two decades (Bennet \& Adamowicz, 2001). It is notable that the management of environmental goods and services is a crucial issue in developing countries. As such, it is crucial to have a glance at the farmers' involvement in managing these unpriced goods and services as primary beneficiaries of agricultural land use in connection with environmental as well as social attributes.

At the start, CM stemming from the conjoint analysis has been employed in marketing and transportation research (Louviere \& Hensher, 1982). And later on, CM method as an option to draw out the values of the effects of the environmental change (Mallawaarachchi et al., 2001) has become famous over the last fifteen years (Adamowicz et al., 1994; Adamowicz et al., 1998) and its advantages over the contingent valuation method and other environmental valuation methods are also mentioned duly (Hanley et al., 1998). As maintained by Adamowicz et al. (1994) and Hanley et al. (2001), choice modelling enables the researcher to estimate relative values of several attributes enriched with descriptions for environmental change as well as for the purpose of policy design. Schmitz et al. (2003) also mentioned the pertinence of the CM, as they are capable of calculating the theoretically correct measures of welfare in the form of implicit prices. Also, in the array of environmental valuation approaches, the $\mathrm{CM}$ is believed to be an appropriate method to value home gardens, given their multiple attributes (Birol et al., 2006a) complemented with its ability to estimate the value of environmental asset as a whole followed by the implicit values of its attributes (Hanley et al., 1998; Bateman et al., 2002).

In this study, CM is used to estimate farmers' utility related to different land use options, with artificially designed changes in areas under main crops and of course the varying levels of environmental and social attributes.

\section{Study Area/Study Design}

The study was conducted amongst farm households in the Konibodom region. Along with other districts of the Soghd oblast, also known as the apricot pot of the country. Figure 1 demarcates the study area.

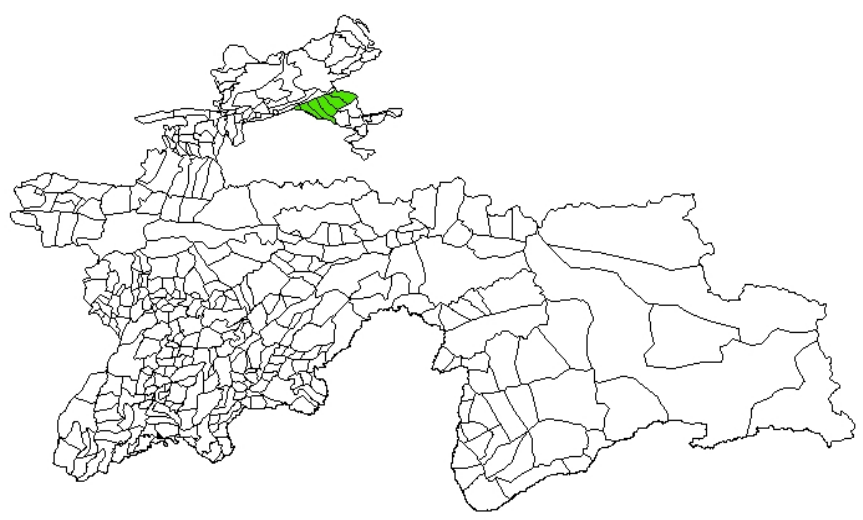

Figure 1. Map of the Study area

Source: own illustration, created using ArcMap 10.0, 2011. 
Whilst applying Choice modelling techniques, it is crucial to identify the pertinent properties of the goods to be valued. It is about the attributes and their levels. Schmitz et al. (2003) emphasizing on this particular stage of survey design, mentioned that providing respondents with a comprehensive package about the environmental good and the valuation task ensures that respondents to deliver well considered answers.

\subsection{Experimental Design of Choice Experiments}

Current study makes use of choice experiment instrument, since they provide evident advantages over other stated preference methods. First of all, they offer an easy way for respondents to make their choices between various alternatives. Second of all, they provide the researcher enough flexibility in designing the hypothetical scenarios. And after all, via marginal WTP estimations they allow the researcher to derive welfare estimates for policy change.

\subsection{Choice Experiment Format and Attributes}

At an early stage series of meetings were held with the representatives of Ministry of Agriculture, State committee on Environmental Protection, State Statistical Committee, and State Land committee, Ministry of melioration and water resources and the Republican Sanitary and epidemiological Service, to discuss the relevant attributes and attribute levels considering the specificities of the study area (Note 2). As such, based on the Focus groups discussions held with various stakeholders, a questionnaire was developed for conducting pre-tests in a study area involving representatives from District Agricultural, Land, Environmental protection and Statistical committees as well as selected number of farmers. Thus, following the discussions with stakeholders and specialists at a different level attributes like agricultural land use scenarios, quality of drinking water, number of trees per hectare, number of workers engaged in agricultural sector, number of species and finally payment vehicle were defined.

Further, considering the percentage share of changes in agricultural land use namely changes in area under various crops, four different scenarios were classified and portrayed as artificial pictures demonstrating the change in the crop area.

For the purpose of water quality selection as a second attribute for this study, the Republican Sanitary and Epidemiological Service were approached.

Since the quality of drinking water is considered to be a substantial ecological constituent of a sustainable land use system (Wronka, 2001), based on the water samples taken from 16 potable water systems within the study area, the level of water contamination with nitrates, nitrites and ammonium were analysed and reported (Note 4).

District Agricultural departments are conducting an inventory of trees within their territories once in a year. This is an official document keeping an account of fruit and decorative trees as well as area under perennial crops and their spacing distance. Hence, going after the discussions with key sector specialists of the districts' Agricultural and Environmental protection committees as a third attribute the number of trees per hectare was selected. The rationale behind the choice for this attribute was the importance of the area expansion for fruits gardens particularly in Northern Tajikistan (Note 3). On the other hand, the northern part is considered to have a comparative advantage in the production of fruits.

In view of the fact that creation of employment opportunities in districts' agricultural sector is of importance, referring to data from District Statistical office, the actual number of workers engaged in agricultural sector was obtained and was defined as another attribute for this study, with further percentage increase in number of jobs created in the study area.

The number of species indicating biodiversity for the study area is also believed to be linked with a sustainable land use. Although the types and the number of species at a national level were availed by FNRBC (2009), it was a challenging task to get detailed data on the number of species and their types at a regional level, taking into account districts. Discussion meetings were held with natural scientists for the survey districts and representatives of the State committee on Environmental protection (Note 5). Despite the difference in landscape location of three districts lying in Ferghana valley, alongside the Syrdarya basin, namely Asht, Konibodom and Isfara, many elements of the fauna were found to be identical. Hereby, subject to the availability of district level data, types and numbers of species like amphibians, reptilians, birds and mammals were deemed under the biodiversity attribute.

Finally, payment vehicle being an important attribute to estimate the implicit prices, were defined. In view of the fact that a payment attribute should be more realistic, a starting point here was to identify an appropriate payment rate which is more less applied on the ground and somehow related to farmers' activities. Resultant from the discussions with districts sector specialists, the calculated amount of 10 somoni was defined as payment 
attribute, an average farmer paying this amount for irrigation water delivery per month per hectare. This amount was considered as a basis with its increase in hundred per cent moving towards 20, and then 30 somoni, respectively. Along with abovementioned payment attributes, 0 somoni was also regarded as zero payment attribute.

The choice of attributes for this study was based on a review of existing relevant literature, current agricultural and environmental policies in Tajikistan which was further complimented with the results of semi-structured interviews conducted in different levels. Attributes selected for this study and their corresponding levels are presented in Table 1.

Table 1. Attributes and Levels

\begin{tabular}{ll}
\hline Attributes & Levels \\
\hline Agricultural land use pattern prioritization & $\begin{array}{l}\text { 1) Current, } \\
\text { 2) Equal allocation of land for cotton and fruits, } \\
\text { 3) Domination of fruits and vegetables only } \\
\text { 4) Domination of cotton only }\end{array}$ \\
\hline $\begin{array}{l}\text { Water quality } \\
\text { (i.e. Nitrate contamination) }\end{array}$ & 10-25 mg/l, $25-55 \mathrm{mg} / 1,55-75 \mathrm{mg} / 1,>75 \mathrm{mg} / 1$ \\
\hline No of trees per ha. & No increase, $5 \%$ increase, $10 \%$ increase, $15 \%$ increase \\
\hline Number of workers in agriculture & No increase, $5 \%$ increase, $10 \%$ increase, $15 \%$ increase \\
\hline Loss in Number of species(biodiversity) & No increase, $5 \%$ increase, $10 \%$ increase, $15 \%$ increase \\
\hline Payment attributes & $0,10,20,30$ TJS \\
\hline
\end{tabular}

The three alternatives presented to farmers are considering different forms of land use scenarios, with land use prioritization towards cash crops or food crops, a balance between both crops, and a status quo option, choosing a current situation. An introductory preamble statement was also provided at the beginning of the choice experiment questions.

\subsection{Designing Choice Sets}

Overall 6 attributes were defined, each taking four levels. This representation takes the form of $4^{6}$ matrices, meaning that this would result in a total of 4096 combinations.

Table 2. Sample choice set

\begin{tabular}{|c|c|c|c|c|}
\hline & Alternative 1 & Alternative 2 & Alternative 3 & $\begin{array}{l}\text { Alternative } 4 \\
\text { (Status Quo) }\end{array}$ \\
\hline $\begin{array}{l}\text { Agricultural land use } \\
\text { pattern prioritization }\end{array}$ & $\begin{array}{c}\text { Option } 2 \text { (Equal } \\
\text { allocation of land } \\
\text { for cotton and fruits) }\end{array}$ & $\begin{array}{c}\text { Option 3(Domination } \\
\text { of fruits and } \\
\text { vegetables only) }\end{array}$ & $\begin{array}{c}\text { Option } \\
\text { 4(Domination of } \\
\text { cotton only) }\end{array}$ & $\begin{array}{r}\text { Option } 1 \\
\text { (Current } \\
\text { situation) }\end{array}$ \\
\hline \multicolumn{5}{|l|}{ Water quality } \\
\hline $\begin{array}{c}\text { (i.e. Nitrate } \\
\text { contamination) }\end{array}$ & $10-25 \mathrm{mg} / 1$ & $55-75 \mathrm{mg} / 1$ & $>75 \mathrm{mg} / 1$ & $10-25 \mathrm{mg} / 1$ \\
\hline No of trees per ha. & $10 \%$ increase & No increase & $5 \%$ increase & No increase \\
\hline $\begin{array}{c}\text { Number of workers in } \\
\text { agriculture }\end{array}$ & $15 \%$ increase & $10 \%$ increase & No increase & No increase \\
\hline $\begin{array}{c}\text { Loss in Number of } \\
\text { species(biodiversity) }\end{array}$ & $5 \%$ increase & No increase & $15 \%$ increase & No increase \\
\hline $\begin{array}{l}\text { Cost to the respondent } \\
\text { per month }\end{array}$ & TJS 30 & TJS 10 & TJS 20 & 0 \\
\hline
\end{tabular}


However, it would have been a difficult task for farmers and almost impossible to evaluate and choose all choice combinations. With the purpose of making survey length practical and avoid or at least reduce respondents' fatigue, it has been decided to employ simple orthogonal main effects design using CBC Sawtooth software (Sawtooth, 1999).

Employing CBC Sawtooth software 'design efficiency for main effects' tool for paper-and-pencil questionnaire design, by including all choice tasks randomly, 128 combinations were generated. As a result, with complete enumeration task generation method applied, a total of 128 combinations were divided in to four versions, each 32 tasks, which later formed in to 8 choice sets per respondent. (i.e. Four alternatives per choice set). An example of a choice set is presented in Table 2 .

To explore the farmers' preferences for different land use options in the area, a choice experiment technique of stated preference methods was used as research methodology. Subsequently, farmers were selected based on the lists provided by District Agricultural department. After several focus group discussions the decision was made to follow the combination of personal interview with 'pick and drop' approaches. Further, questionnaires were distributed during the monthly meetings held at the District Agricultural Department to 120 farmers, covering all the settlements and locations of the district. Of which, 117 farmers being representatives of all locations of the district returned completed sets of questionnaires. In order to compliment the survey data, secondary data was collected additionally from official statistics and other agencies, key informants and focus group discussions with the experts from the field.

\section{Results and Discussion}

Based on the data available for the analysis, several types of models were specified and estimated. This was done with reference to different types of coding like, effects-type dummy coding and linear coding. Later on, models with the highest value of the log likelihood function were tested to select an appropriate model to be retained for further welfare analysis. Therefore, the indirect utility farmers derive from the land use options could be specified as:

$$
\begin{aligned}
& V_{i j}=\beta+\beta_{1}\left(Z_{\text {landuse } 2}\right)+\beta_{2}\left(Z_{\text {landuse } 3}\right)+\beta_{3}\left(Z_{\text {landuse } 4}\right)+\beta_{4}\left(Z_{\text {NitrateVhigh }}\right)+\beta_{5}\left(Z_{\text {Nitratehigh }}\right) \\
& +\beta_{6}\left(Z_{\text {Nitratelow }}\right)+\beta_{7}\left(Z_{\text {Trees }}\right)+\beta_{8}\left(Z_{\text {Wor ker s }}\right)+\beta_{9}\left(Z_{\text {Biodiversity }}\right)+\beta_{10}\left(Z_{\text {cost }}\right)
\end{aligned}
$$

Where $\beta$ denotes alternative specific constant (ASC), which enters the functional form and takes the value of 1 if alternatives other than status quo option were chosen. Variables $\beta_{1}$ to $\beta_{10}$ are representing the vector of coefficients describing attributes associated with one or another types of agricultural land use options. This is in fact the simplest representation of the random utility model specification with the aim of looking into the effects that attributes may have on the farmer's preferences for various agricultural land use options.

In the above model formulation, land use options and levels of nitrate contamination in drinking water are entered into the function as dummy variables. Other variables enter the functional form in different ways, namely as a dummy or in linear form depending on the types of the model to be estimated. All the models of choice data were estimated using LIMDEP 8.0 NLOGIT 3.0.

\subsection{Random Parameters Logit Model}

Unlike conditional logit model, random parameters logit is not subject to independence of irrelevance alternatives (IIA) assumption, where the latter considers unconditional and unobserved heterogeneity in preferences of respondents. However, according to Train (2003), whilst estimating random parameters logit, an assumption should be made regarding the distribution of the random parameters.

As the main concerns in a choice modelling process are the properties of incompleteness, randomness and distinctiveness, which in turn put under question the appropriateness of the models estimations, there is a need to search for another alternative approaches for choice modelling. Herein, the Random Parameters Logit could serve as an alternative, famousness of which has grown along with the development of discrete choice modelling (McFadden \& Train, 2000).

In a random parameters logit via relaxation of the IIA property, one can specify the model in a way that each choice alternative can be correlated for each respondent (Hensher \& Greene, 2001).

The Random Parameters logit model takes the multinomial logit model as a basis and simplifies it by allowing the coefficients of systematic variables to vary across the individuals. This is done through the division of unobservable component of the utility function into two: one which is correlated over alternatives and the second part is identically and independently distributed, as it is given by: 


$$
U_{i j}=\beta X_{i j}+\eta_{i} X_{i j}+\varepsilon_{i j}
$$

Where, $X_{i j}$ is a vector of observed attributes of alternative within a choice set, $\beta$ is the vector of coefficients of these attributes, $\eta_{\eta}$ denotes the vector of $\mathrm{k}$ standard deviation parameters and, $\varepsilon_{i j}$-random portion of utility. Thus, $\eta_{i} X_{i j}+\varepsilon_{i j}$ is the unobserved portion of utility because of the influence of $\eta_{\eta}$, which is correlated across individuals (Train, 1998).

The probability of individual $\mathrm{i}$, choosing alternative $\mathrm{j}$ in a choice situation $\mathrm{t}$, lets assume is expressed as following:

$$
P\left(j \mid \mu_{i}\right)=\frac{\exp \left(\alpha_{j i}+\gamma_{j} z_{i}+\eta_{i} x_{j i}\right)}{\sum_{j=1}^{J} \exp \left(\alpha_{j i}+\gamma_{j} z_{i}+\eta_{i} x_{j i}\right)}
$$

Where, $\alpha_{j i}$ is a fixed or random alternative specific constant for $\mathrm{i}$ individuals and $\mathrm{j}$ alternatives $(\mathrm{j}=1, \ldots, \mathrm{J})$, $\gamma_{j} z_{i}$ is a vector of systematic parameters responsible for individuals characteristics, $\eta_{j i}$ denotes a parameter vector which is randomly distributed over individuals, $z_{i}$ accounts for individual-specific characteristics, $x_{j i}$ is the vector of attributes and $\mu_{j i}$ is the individual specific random disturbance of unobserved heterogeneity (Louviere et al., 2000a; Train, 1998).

However, in order to estimate RPL model it is necessary to assume how the coefficients are distributed over the individuals (Train, 1997).

Moreover, the state-of-the-art application of random parameters logit in various fields have confirmed that this model is far better than conditional logit model in terms of overall fit and welfare measures (Carlsson et al., 2003; Morey \& Rossman, 2003; Birol et al., 2006a; 2006b).

Thus, in order to relax the IIA assumption and further examine the sources of heterogeneity amongst farmers, in this stage random parameters logit was estimated. As maintained by Train (2003), normally distributed parameters, means and standard deviations of the coefficients can provide information on to what extent respondents put either positive or negative value on the environmental attribute.

Consistent with steps recommended by Hensher et al. (2005), for the estimation of RPL, at the beginning all the parameters except the cost parameter were specified to be normally distributed (Train, 1998; Revelt \& Train, 1998). Then, all the random parameters having insignificant standard deviations were re-estimated, and this time as non-random parameters. Hence, the estimation of random parameters logit with normally distributed random parameters was based on 500 Halton draws. In the estimation of random parameters logit to account for farmer's preferences heterogeneity, attribute variables entered the random utility function in a combined form. Land use option attributes along with quality of drinking water, denoting nitrate contamination have entered the utility function as dummy variables. Other attributes like, number of workers in agricultural sector, number of trees, increase in number of species standing for biodiversity and cost attribute entered the utility function in a linear continuous form.

Attribute values were linearised according to the formulae for orthogonal polynomial coding (Louviere et al., 2000).

The results of the random parameters logit estimations are reported in Table 3. It must be noted that the results of the conditional logit model demonstrated in this table are not considered for further interpretations and serve as a benchmark against the estimated random parameters logit model.

As can be seen in Table 3, the results reveal that the random parameters logit model estimations reveal significant and large standard deviations for land use option, biodiversity and number of workers attributes' coefficients. This means that preferences heterogeneity exists among the farmers. Comparing to the benchmark CL model which is reported in the first column of the Table 3, the log-likelihood value for the RPL model (-1155, 870 ) is higher than that of the CLM model with -1208, 583. In conditional logit model almost all attributes except three corresponding levels of nitrate namely medium, high and very high are significant. In contrast, the random parameters logit model estimates show that very high level of nitrate in drinking water is significant and has negative sign as expected. Two other, medium and high levels of nitrate in drinking water are also insignificant in the RPL model. The cost attribute parameter is as expected, significant and has negative sign in both model results. Also, it could be added that, given the unconditional and unobserved heterogeneity for the corresponding attributes, there is an indication that some farmers might prefer lower levels of these attributes. 
The log-likelihood ratio test between the two models results the value of 105,426 , which rejects the null hypothesis that the parameters in the regressions are equal at $0,05 \%$ significance level. This implies that comparing between models, a model fit improvement can be achieved via employment of random parameters logit, and therefore the random parameters logit is deemed to be appropriate model for the analysis of the data in this study.

Table 3. Results of the RPL model with and without interactions

Model 1: No Interactions

Model 2: Interactions

\begin{tabular}{|c|c|c|c|c|c|c|}
\hline \multirow[t]{2}{*}{ Variable } & \multirow[t]{2}{*}{ CLM } & \multicolumn{2}{|c|}{ RPL } & \multirow[t]{2}{*}{ CLM } & \multicolumn{2}{|c|}{ RPL } \\
\hline & & Mean & SD & & Mean & SD \\
\hline Land use option 2 & $\begin{array}{c}-0,520809 * * * \\
(-4,754)\end{array}$ & $\begin{array}{c}-0,77096^{* * *} \\
(-4,470)\end{array}$ & $\begin{array}{c}1,12974 * * * \\
(5,982)\end{array}$ & $\begin{array}{c}-0,50457 * * * \\
(-4,600)\end{array}$ & $\begin{array}{c}-0,756812 * * * \\
(-4,345)\end{array}$ & $\begin{array}{c}1,144956 * * * \\
(6,010)\end{array}$ \\
\hline Land use option 3 & $\begin{array}{c}-0,959102 * * * \\
(-7,963)\end{array}$ & $\begin{array}{c}-1,4465 * * * \\
(-6,632)\end{array}$ & $\begin{array}{c}1,36802 * * * \\
(6,078)\end{array}$ & $\begin{array}{c}-1,00177 * * * \\
(-8,203)\end{array}$ & $\begin{array}{c}-1,474262 * * * \\
(-6,745)\end{array}$ & $\begin{array}{c}1,367145^{* * *} \\
(6,019)\end{array}$ \\
\hline Land use option4 & $\begin{array}{c}-0,871369 * * * \\
(-7,369)\end{array}$ & $\begin{array}{c}-1,13827 * * * \\
(-6,147)\end{array}$ & $\begin{array}{c}1,45791 * * * \\
(6,291)\end{array}$ & $\begin{array}{c}-0,895118^{* * *} \\
(-7,510)\end{array}$ & $\begin{array}{c}-1,425087 * * * \\
(-6,209)\end{array}$ & $\begin{array}{c}1,475387^{* * *} \\
(6,301)\end{array}$ \\
\hline Nitrate very high & $\begin{array}{c}-0,200219 \\
(-1,613)\end{array}$ & $\begin{array}{c}-0,23932^{*} \\
(-1,701)\end{array}$ & - & $\begin{array}{c}-0,240988^{*} \\
(-1,929)\end{array}$ & $\begin{array}{c}-0,294259^{* *} \\
(-2,074)\end{array}$ & - \\
\hline Nitrate high & $\begin{array}{c}-0,072308 \\
(0,601) \\
\end{array}$ & $\begin{array}{r}0,07015 \\
(0,502) \\
\end{array}$ & - & $\begin{array}{c}0,103152 \\
(0,853) \\
\end{array}$ & $\begin{array}{c}0,107843 \\
(0,770)\end{array}$ & - \\
\hline Nitrate medium & $\begin{array}{c}0,065404 \\
(0,538)\end{array}$ & $\begin{array}{c}0,106976 \\
(0,778)\end{array}$ & - & $\begin{array}{c}0,062125 \\
(0,509)\end{array}$ & $\begin{array}{c}0,085481 \\
(0,617)\end{array}$ & - \\
\hline Biodiversity & $\begin{array}{c}-0,002683^{*} \\
(-1,659)\end{array}$ & $\begin{array}{c}-0,003859 * \\
(-1,938)\end{array}$ & $\begin{array}{c}0,0073245^{* *} \\
(2,788)\end{array}$ & $\begin{array}{c}-0,003086^{*} \\
(-1,903)\end{array}$ & $\begin{array}{c}-0,004298 * * \\
(-2,159)\end{array}$ & $\begin{array}{c}0,007211 * * * \\
(2,639)\end{array}$ \\
\hline Workers & $\begin{array}{c}-0,002675^{* * * *} \\
(-6,746)\end{array}$ & $\begin{array}{c}- \\
(-6,412)\end{array}$ & $\begin{array}{c}0,0002571 * * \\
(3,413)\end{array}$ & $\begin{array}{c}-0,0002318^{* * * *} \\
(-5,628) \\
\end{array}$ & $\begin{array}{c}-0,0003181 * * * \\
(-5,576)\end{array}$ & $\begin{array}{c}0,0002343 * * \\
(3,033)\end{array}$ \\
\hline Trees & $\begin{array}{c}-0,01626^{* * * *} \\
(-4,212)\end{array}$ & $\begin{array}{c}-0,01903 * * * \\
(-4,312)\end{array}$ & - & $\begin{array}{c}-0,016098 * * * \\
(-4,093)\end{array}$ & $\begin{array}{c}-0,018972 * * * \\
(-4,254)\end{array}$ & - \\
\hline Cost & $\begin{array}{c}-0,008322 * * \\
(-2,395)\end{array}$ & $\begin{array}{c}-0,01003 * * \\
(-2,402)\end{array}$ & - & $\begin{array}{c}-0,009124 * * * \\
(-2,644)\end{array}$ & $\begin{array}{c}-0,010631 * * \\
(-2,557)\end{array}$ & - \\
\hline ASC & $\begin{array}{c}1,13871 * * * \\
(7,085)\end{array}$ & $\begin{array}{c}1,39447 * * * \\
(7,593)\end{array}$ & - & $\begin{array}{c}1,778451^{* * *} \\
(4,513)\end{array}$ & $\begin{array}{c}2,194864 * * * \\
(4,635)\end{array}$ & - \\
\hline Gender*ASC & & - & & $\begin{array}{c}-0,790401 * * \\
(-2,119)\end{array}$ & $\begin{array}{c}-0,979302 * * \\
(-2,154)\end{array}$ & - \\
\hline Area $>50 *$ ASC & & - & & $\begin{array}{c}0,286979 * * * \\
(3,250)\end{array}$ & $\begin{array}{c}0,311262^{* * *} \\
(3,002)\end{array}$ & - \\
\hline Log-likelihood & $-1208,583$ & $-1155,870$ & & $-1200,743$ & $-1148,977$ & \\
\hline$R^{2}$ & 0,06858 & 0,1092 & & 0,07462 & 0,1145 & \\
\hline $\begin{array}{l}\text { Number of } \\
\text { respondents }\end{array}$ & 117 & & & & 17 & \\
\hline $\begin{array}{l}\text { Number of } \\
\text { choices }\end{array}$ & 936 & & & & 36 & \\
\hline
\end{tabular}

Source: Own calculation, 2011; Note: t-Statistics are in parentheses. * $* *$ and $* * *$ denote significances at $10 \%$, $5 \%$ and $1 \%$ respectively.

\subsection{Random Parameter Logit Model with Interactions}

Although the unobserved heterogeneity could be accounted for in the random parameters model, however it fails to account for the sources of heterogeneity, simply put, those who could be affected by a policy change (Boxall $\&$ Adamowicz, 2002). As a result, including variables formed as interactions between respondent-specific social, economic and attitudinal characteristics with choice attributes or with alternative specific constant (ASC) in utility function, can help to detect the sources of observed preference heterogeneity. In this manner, random parameter logit is able to capture preference variation in terms of random heterogeneity and conditional heterogeneity in tests, and thus improving the fit of the model (Revelt \& Train, 1998; Birol et al., 2006a;).

Various interaction terms of farmers' socio-economic and attitudinal characteristics with the choice specific attributes and alternative specific constant were included in the utility function and several models were estimated. After insignificant interaction terms were deleted one by one, due to the fact that most of them appeared to be insignificant, the decision was taken not to include them in subsequent estimations. 
The model that includes interaction terms with 'Gender*ASC' and 'Area above 50ha*ASC' was found to fit the data very well. In interaction term 'AREA*ASC', denoting that those farmers with more than 50 hectares of land and their relationship with alternative specific constant, variable "area" entered as dummy variable, taking the value of 1 , if land size is above 50 hectares and 0 otherwise.

Accordingly, extending the indirect utility function to include these two variables, the random parameter logit model with interactions was estimated.

Similarly to the previously estimate random parameters logit, in random parameters logit with interactions, estimation of the model was assumed with normally distributed random parameters and was based on 500 Halton draws. The results of the model estimation are presented in Table 2 (Model 2: Interactions).

Mean effects of all the land use options, number of workers, and number of trees are all significant at $1 \%$ level. Mean effects for all other attribute parameters are significant at $5 \%$ level, except medium and high levels of the quality of drinking water. This is in fact a case in almost all estimated models.

Interaction term, 'area *cost' was found to be significant, and therefore considered in further analysis. Interaction term 'AREA*ASC' showed a significant and positive sign, meaning that those having less than 50 hectares of land, are positively concerned and prefer the current situation. As per interaction term 'Gender*ASC', it is significant and has a negative sign. This indicates that female farmers in the study area were choosing changed options, moving away from the 'status quo' option. The cost variables in both random parameter models are almost equal with $-0,1003$ in the first RPL model and -0, 1063 in the second model with interactions.

The significance of the parameters on the standard deviations of the specific choice attributes coefficients demonstrates whether tastes differences significantly fluctuate amongst the farmers. According to the results presented in the Table 3, where estimated standard deviations of the coefficients are highly significant at $1 \%$ level, this could be seen as a fact that these parameters in actual fact vary considerably across farmers.

In order to test whether the random parameters logit with interaction terms is an improved model over the basic random parameters logit without interactions, a likelihood ratio test was conducted (Ben-Akiva \& Lerman, 1985). It could be seen that the model has higher overall fit in comparison to other conditional logit and random parameters logit models, with a $R^{2}$ of 0,11 . The likelihood ratio test LL ratio test suggest that allowing interaction terms to be included in the model yields superior results, with test statistic of $-2[-1155,87+1148,977]=13,786$ exceeding the $\chi_{0,05}^{2}(3)$ critical value of 9,487 . Thus, taking into account the significant standard deviations of the attribute parameters in model results and likelihood ratio test conducted, it can be said that overall model fit is achieved with the inclusion of socio-economic and attitudinal variables. Hence the model could be retained for further consideration and CS calculation.

\section{Estimation of Willingness to Pay}

According to Bateman et al. (2002) the choice experiment method is compatible with utility maximization and demand theory. And the marginal willingness to pay for an attribute in the choice experiment is the ratio of that attribute coefficient and payment attribute coefficient (Morrison et al., 1999). Further, right after the model estimation is done, and parameters are obtained, welfare measures can be determined in the form of marginal willingness to pay. This procedure is carried out via estimation of marginal rate of substitution between the change in land use options with other socio-environmental attributes and the coefficient of the payment attribute which symbolizes marginal utility of income.

Table 4 reports the marginal willingness to pay values or, implicit prices for each of the attributes and for the average farmer resultant from both, the random parameters logit (basic) and the random parameters logit with interaction terms. Since the parameter coefficients estimated are stochastic, there is a need to calculate the confidence intervals for them. The implicit prices and confidence intervals were estimated using the Delta method (Wald procedure) in LIMDEP 8.0 NLOGIT3.0.

The calculated implicit prices are reported only for significant coefficients. The utility of increase in number of workers in the farming sector of the area has low value, and similar low valuations also were reported in other studies (Bennett et al., 2004; Colombo et al., 2005).

As can be seen in Table 3, farmers have a positive marginal willingness to pay for the changes in land use options moving away from the 'status quo' situation. 
Table 4. RPL model implicit prices for land use options attributes - with and without interactions (TJS/month/farmer)

\begin{tabular}{|lcc|cc|}
\multicolumn{1}{c}{} & \multicolumn{2}{c}{$\begin{array}{c}\text { Model 1: Implicit Prices without } \\
\text { Interactions }\end{array}$} & \multicolumn{2}{c|}{$\begin{array}{c}\text { Model 2: Implicit Prices with } \\
\text { Interactions }\end{array}$} \\
\begin{tabular}{|lcc|cc|}
\multicolumn{1}{|c}{ Attributes } & Implicit Price & $\mathbf{9 5} \%$ C.I. & Implicit Price & $\mathbf{9 5} \%$ C.I. \\
\hline Land use option 2 & 1,876 & $(0,941 ; 2,811)$ & 1,9480 & $(0,968 ; 2,928)$ \\
\hline Land use option 3 & 1,793 & $(0,888 ; 2,699)$ & 1,8830 & $(0,921 ; 2,846)$ \\
\hline Land use option 4 & 0,005 & $(0,002 ; 0,007)$ & 0,0004 & $(0,000 ; 0,001)$ \\
\hline Nitrate very high & 0,050 & $(0,045 ; 0,056)$ & 0,0057 & $(0,000 ; 0,011)$ \\
\hline Trees & $-0,091$ & $(-0,449 ; 0,267)$ & $-0,1425$ & $(-0,513 ; 0,228)$ \\
\hline Workers & $-0,139$ & $(-0,496 ; 0,218)$ & $-0,1129$ & $(-0,477 ; 0,251)$ \\
\hline Biodiversity & 0,025 & $(0,009 ; 0,041)$ & 0,0251 & $(0,008 ; 0,042)$ \\
\hline SD Land use option 2 & $-1,809$ & $(-2,662 ;-0,955)$ & $-2,9001$ & $(-4,628 ;-1,172)$ \\
\hline SD Land use option 3 & $-1,465$ & $(-2,385 ;-0,546)$ & $-1,5129$ & $(-2,482 ;-0,543)$ \\
\hline SD Land use option 4 & $-1,774$ & $(-2,739 ;-0,810)$ & $-1,8065$ & $(-2,801 ;-0,812)$ \\
\hline SD Biodiversity & $-0,003$ & $(-0,006 ;-0,001)$ & $-0,0003$ & $(-0,001 ; 0,000)$ \\
\hline SD Workers & $-1,891$ & $(-2,906 ;-0,876)$ & $-1,9495$ & $(-3,019 ;-0,880)$ \\
\hline
\end{tabular}
\end{tabular}

Source: Own Calculation.

It is visible that farmers give more preference to land use options two and three, emphasising more on fruits and vegetables production scenarios.

The marginal willingness to pay for land use option 2 as it is reported in the Table 4 (Model 2) is TJS 1, 95 and a standard deviation of TJS $-2,90$ per month per farmer. Increase in average units of trees as well as worker attributes are seemingly to be welfare deteriorating for farmers in the study area with TJS $(-0,14)$ and TJS $(-0$, 11) per month per farmer.

Based on the implicit prices calculated which were referring to monthly payments per farmer, annual implicit prices were also calculated.

\subsection{Welfare Estimates for Alternative Land Use Scenarios}

Implicit prices reported in the tables of the preceding section can not provide the estimation of compensating surplus (CS) for the hypothetical land use scenarios. For the purpose of calculating farmers compensating surplus for different land use options over the current situation, we construct three possible land use scenarios.

- Scenario 1- equalized crop land allocation: Land use option 2, Number of trees increases at high level, Number of workers increase at high level, nitrate contamination high, biodiversity species loss at high level.

- Scenario 2- Only fruits and vegetables: Land use option 3, Number of trees increases at very high level, Number of workers increase at very high level, nitrate contamination medium, biodiversity species loss at medium level.

- Scenario 3-Cotton domination (almost $80 \%$ ): Land use option 4, Number of trees increases at medium level, Number of workers increase at medium level, nitrate contamination very high, biodiversity species loss at very high level.

Thus, as a next step for each of the constructed hypothetical land use scenarios welfare measures were calculated for the average farmer in the study area. Making use of a 'state-of-the-world' approach (Holmes \& Adamowicz, 2003), compensating surplus can be calculated by summation of the relevant marginal willingness to pay values.

Out of the three scenarios, first one is supposed to be equal allocation of land for cotton and fruits production. The thing is referring to the 'status quo' situation, currently more than 50 per cent of cropland is allocated to cotton and remaining to fruits and other cereal and forage crops. Therefore, allocating more of cotton land for the sake of fruits growing is considered to be an initial change situation, where both crops occupy equal amount of crop land. Table 5, reports the calculated CS measures for each of three land use scenarios. The results of the Table 5 on compensating surplus calculation reveal that farmers place high values on the first and second land use options, whereas the first land use option is preferred more and farmers have a higher measure of willingness to pay for this option. It is discovered that farmers have a negative willingness to pay for the land use scenario 3 , 
suggesting that farmers in the study area do not prefer and most probably will not support the change in land use options to this extreme, where cotton only dominates.

Table 5. Compensating surplus for various land use options

\begin{tabular}{cc}
\hline Scenario & CS per farmer per year \\
\hline Land use scenario1 & 20,79 \\
Land use scenario2 & 20,01 \\
Land use scenario3 & $-2,58$
\end{tabular}

Source: Own calculation

\section{Conclusion}

Overall, the analysis carried out in this study provides a remarkable picture as long as environmental valuation of agricultural land use is concerned in the study area and in the country as well. The findings vividly demonstrate that farmers as primary users of agricultural land are concerned about the effects of land use on environment, as far as study area is concerned. When farmers were asked to define the relative importance of the land use options symbolizing different cropping systems and other socio-economic and environmental elements like, water quality, biodiversity, number of trees and numbers of workers in the area associated with these options were all considered as very important issues. One important aspect here was that, once practicing more environmentally harmful agricultural practices, farmers are willing to pay for the pollution, the amount of $0.30 \mathrm{TJ}$ somoni per farmer per year.

Average willingness to pay for the two proposed land use scenarios have found to be TJ somoni of 23,4 and 22,6 per year. Third land use scenario with the dominance of cotton became negative in terms of average willingness to pay, denoting this scenario unacceptability.

Female farmers in the study area are in favour of changes in agricultural land use options by choosing to move away from the 'status quo' option. Farmers with less than 50 hectares of land in their possession, are less likely to prefer changed situations, deciding on to stay with the current situation.

This implicates that a decision for land allocation under different crops is jointly associated with other socio-economic and environmental factors, influencing one another. Thus, it can be concluded that farmers in the study area are favouring and in support of government initiated policies in the sector.

This study contributes to the sparse literature on the estimation of non-use values of agricultural land use, employing a choice experiment. The results of this study show that there are positive and negative non-use values associated with social, economic and environmental attributes of the agricultural land use. This study provided useful information for the policy level in designing environmentally less harmful and economically efficient agricultural policies, taking into account the interests of 'meso' and 'micro' levels.

\section{Acknowledgements}

This study is made possible by the support of the German Academic Exchange Service (DAAD) funded project CLINCA (Climate change network for Central Asia), which is duly acknowledged.

\section{References}

Adamowicz, W. L., Louviere, J., \& Williams, M. (1994). Combining Stated and Revealed Preference Methods for Valuing Environmental Amenities. Journal of Environmental Economics and Management, 26, 271-292. http://dx.doi.org/10.1006/jeem.1994.1017

Adamowicz, W., Boxall, P., Williams, M., \& Louviere, J. (1998). Stated Preference Approaches for Measuring Passive Use Values: Choice Experiments and Contingent Valuation. American Journal of Agricultural Economics, 80, 64- 75.

Aidarov, I. P., \& Korolkov, A. I. (2003). Perspektivy Razvitiya Kompleksnyh Meropriyatiy V Rossi (Further outlooks for integrated land reclamation in Russia). Moscow, Russian.

Bateman, I. J., Carson, R. T., Hanemann, M., Hanley, N., Hett, T., Jones-Lee, M., ... Swanson, J. (2002). Economic Valuation with Stated Preference Techniques - A Manual. Cheltenham. 
Bennett, J., \& Adamowicz, V. (2001). Some Fundamentals Of Environmental Choice Modelling. In Bennett, J., \& R. Blamey (Eds.), The choice modelling approach to environmental valuation. Cheltenham.

Ben-Akiva, M., \& Lehrman, S. R. (1985). Discrete Choice Analysis: Theory and Application to Travel Demand. Cambridge, M. A.: MIT Press.

Birol, E., Smale, M., \& Gyovai, Á. (2006a). Using a choice experiment to estimate farmers' valuation of agricultural biodiversity on Hungarian small farms. Environmental and Resource Economics, 34(4), 439-469. http://dx.doi.org/10.1007/s10640-006-0009-9

Birol, E., Kontoleon, A., \& Smale, M. (2006b). Farmer demand for agricultural biodiversity in Hungary's transition economy: A choice experiment approach. In Smale, M. (Ed.), Valuing Crop Biodiversity on Farms during Economic Change. Wallingford: CAB International.

Boxall, P. C., \& Adamowicz, W. L. (2002). Understanding heterogeneous preferences in random utility models: a latent class approach. Environmental and Resource Economics, 23, 421-446. http://dx.doi.org/10.1023/A:1021351721619

Carlsson, F., Frykblom, P., \& Lijenstolpe, C. (2003). Valuing wetland attributes: An application of choice experiments. Ecological Economics, 47, 95-103. http://dx.doi.org/10.1016/j.ecolecon.2002.09.003

Colombo S., Hanley N., \& Calatrava-Requena J. (2005). Designing policy for reducing the off-farm effects of soil erosion using choice experiments. Journal of Agricultural Economics, 56(1), 81-95. http://dx.doi.org/10.1111/j.1477-9552.2005.tb00123.x

Ergasheva, M. A. (2009). Effektivnost' Ispol'zovaniya Prirodno-Resursnogo Potenciala V. Selskom Khozyaistve Efficacy of natural resource potential use in Agricultural sector, Thesis abstracts, Dushanbe, Russian.

FNRBC. (2009). Fourth national report on biodiversity conservation republic of Tajikistan. Dushanbe.

Government of the Republic of Tajikistan, Order on ,The state program for the enhancement of fruits and vegetables production and development of gardening for the period of 2007-2010', from April 6, 2007, N.194.

Government of the Republic of Tajikistan, Decree on 'Additional measures for the development of horticultural sector for the period of 2010-2014', from August 29, 2009, N.683.

Greene, W. H. (2002). LIMDEP8.0 /NLOGIT version 3.0 reference guide. Econometric Software. New York, USA.

Hanemann, W. M. (1994). Valuing the environment through contingent valuation. Journal of Economic Perspectives, 8(4), 19-43. http://dx.doi.org/10.1257/jep.8.4.19

Hanley, N., Spash, S., \& Walker, L. (1996). Problems in valuing the benefits of biodiversity conservation. Environmental and Resource Economics, 5, 249-272. http://dx.doi.org/10.1007/BF00691519

Hanley, N., Mourato, S., \& Wright, R. (2001). Choice modelling approaches: A superior alternative for environmental valuation? Journal of Economic Surveys, 15, 3.

Hanley, N., Wright, R. E., \& Adamowicz, V. (1998). Using Choice Experiments to Value the Environment Design Issues, Current Experience and Future Prospects. Environmental and Resource Economics, 11(3-4), 413-428.

Hensher, D. A., \& Greene, W. H. (2001). The mixed logit model: The state of practice and warnings for the unwary. Working Paper, School of Business, The University of Sidney.

Hensher, D. A., Rose, J. M., \& Greene, W. H. (2005). Applied Choice Analysis - A Primer. Cambridge.

Holmes, T. P., \& Adamowicz, W. L. (2003). Attribute- Based Methods. In P. A. Champ, K. J. Boyle, \& T. C. (Eds), Brown A Primer on Non- Market Valuation. Dordrecht, The Netherlands: Kluwer Academic Publishers. Lancaster, K. J. (1966). A new approach to consumer theory. Journal of Political Economy, 74 (2), 132-157.

Louviere, J. J., \& Hensher, D. A. (1982). On the design and analysis of Simulated choice or allocation experiments in Travel choice modelling. Transportation Research Record, 890, 11-17.

Louviere, J. J., Hensher, D. A., \& Swait, J. D. (2000). Stated Choice Methods - Analysis and Application. Cambridge.

Luce, D. (1959). Individual Choice Behaviour. New York, NY: John Wiley. 
Mallawaarachchi, T., \& Quiggin, J. (2001). Modelling socially optimal land allocations for sugar cane growing in North Queensland: a linked mathematical programming and Choice Modelling study. Australian Journal of Agricultural and Resource Economics, 45, 383-409. http://dx.doi.org/10.1111/1467-8489.00149

McFadden, D. (1974). Conditional logit analysis of qualitative choice behaviour. In Zarembka, P. (Ed.), Frontiers in Econometrics (pp. 105-142). New York.

McFadden, D. (1978). Modelling the choice of residential location. In Karlqvist, L., Lindquist, L., Snickars, F., \& J. Weibull (Eds.), Spatial Interaction Theory and Planning Models (pp. 75-96). Amsterdam.

McFadden, D., \& K. Train. (2000). Mixed MNL Models for Discrete Response. Journal of Applied Econometrics, $15(5), \quad$ 447-470. http://dx.doi.org/10.1002/1099-1255(200009/10)15:5<447::AID-JAE570>3.0.CO;2-1

Morey, E. R., \& Rossmann, K. G. (2003). Using stated-preference questions to investigate variations in willingness to pay for preserving marble monuments: classic heterogeneity, random parameters, and mixture models. Journal of Cultural Economics, 27(4), 229. http://dx.doi.org/10.1023/A:1026365125898

Revelt, D., \& K. Train. (1998). Mixed logit with repeated choices: households choice of appliance efficiency level. Review of Economics and Statistics, 53, 647-657. http://dx.doi.org/10.1162/003465398557735

Morrison M., Bennet J., \& Blamey R. (1999). Valuing improved wetland quality using choice modeling. Water Resources Research, 35(9), 2805-2814. http://dx.doi.org/10.1029/1999WR900020

NEAP. (2006). National Environmental Action Plan, Approved by the Government of Republic of Tajikistan, \#191, May 3, 2006, Dushanbe.

Sawtooth Software. (1999). CBC User Manual. Version 2.0., Sequim, WA.

Schmitz, K., Schmitz, P. M., \& Wronka, T. C. (2003). Integrated Ecological and Economical Valuation of Land Use Systems. In Kissling, M., Schmitz, K., Schmitz, P. M., \& Wronka, T. C. (Eds.), Pricing Environmental Services of Agriculture (pp. 131-152). Kiel.

Sheraliev, E. N. (2009). Special Aspects of ecological problems of agricultural land use in Tajikistan. Tajik State National university research journal, Dushanbe "Sino", ISSN2074-1847, pp.14-19.

SLC. (2007). State Land Committee of the Republic of Tajikistan: Concept of Land use in the Republic of Tajikistan, concept document, Dushanbe.

SSC. (2008). Tajikistan Agricultural Statistical Book: Statistical yearbook, Dushanbe.

SSC. (2009). State Statistical Committee of the Republic of Tajikistan: Regions of the Republic of Tajikistan, Dushanbe.

SSC. (2009). Tajikistan Agricultural Statistical Book: Statistical yearbook, Dushanbe.

Thurstone, L. (1927). A law of comparative judgement. Psychological Review, 34(4), 272-286. http://dx.doi.org/10.1037/h0070288

Train, K. E. (1998). Recreation demand models with taste differences over people. Land Economics, 74, 230-239. http://dx.doi.org/10.2307/3147053

Train, K. (1997). Mixed Logit Models for Recreation Demand. In C. Kling, \& J. Herriges (Eds), Valuing the Environment Using Recreation Demand Models. Lyme, NH: Edward El-gave.

Train, K. (2003). Discrete Choice Methods with Simulation. Cambridge, UK: Cambridge University Press. http://dx.doi.org/10.1017/CBO9780511753930

UNECE. (2004). Environmental performance reviews. No21, Tajikistan, New York and Geneva, 2004, ISSN 1020-4563.

World Bank Report Tajikistan. (2008). Country Environmental Analysis. May 15, 2008, Report No.43465-TJ.

Wronka, T. C. (2001). Biodiversity and drinking water quality: an analysis of values and determinants of willingness to pay. In Peters, G. H., \& P. Pingali (Eds.), Tomorrow's Agriculture: Incentives, Institutions, Infrastructure and Innovations (pp. 784-785). Proceedings of the 24th International Conference of Agricultural Economists, Ashgate. 


\section{Notes:}

Note 1. According to the Law of the Republic of Tajikistan. On Dehkan Farms, dehkan farm is a term for peasant farms.

Note 2. Initially meeting was held at the Ministry of agriculture to discuss the purpose of the survey and an official letter was obtained to initiate the survey. (September 2008) Later on communications were held with Republican SES, SLC, SSC and SCEP September, November 2008 and February-March 2009.

Note 3. Letter from the Republican Sanitary and Epidemiological service (SES), September 2008.

Note 4. Government decrees and orders regarding enhancement of fruits and vegetables production.

Note 5. Communication with Dustov. Deputy to the Chairman of State Committee on Environmental Protection, April 11-14, 2009. 